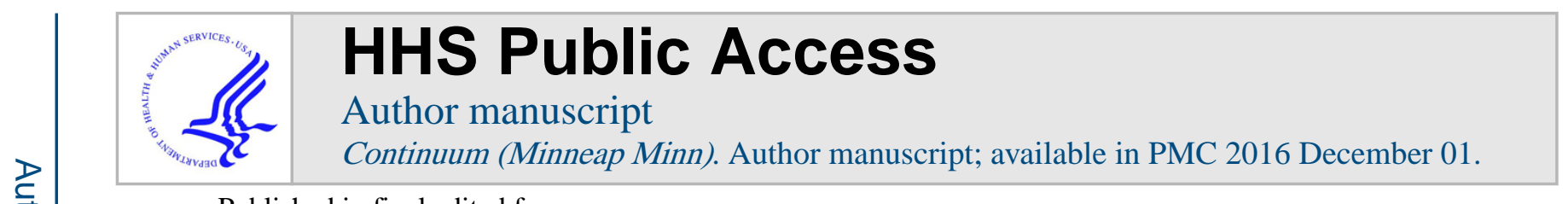

Published in final edited form as:

Continuum (Minneap Minn). 2015 December ; 21(6 NEUROINFECTIOUS DISEASE): 1599-1611. doi: 10.1212/CON.0000000000000240.

\title{
Arbovirus Infections
}

\section{J. David Beckham, MD and Kenneth L. Tyler, MD, FAAN}

\begin{abstract}
Purpose of Review-Arbovirus (arthropod-borne virus) infections are increasingly important causes of neurologic disease in the United States through both endemic transmission and travelassociated infections. This article reviews the major arbovirus infections that can cause neurologic disease likely to be encountered in the United States.
\end{abstract}

Recent Findings-West Nile virus continues to be an important cause of epidemic encephalitis, while emerging arbovirus infections such as dengue and chikungunya have rapidly expanded their geographic distribution. As emerging arboviruses expand in new geographic regions, neurologic abnormalities are reported in new patient populations.

Summary-Emerging arbovirus infections are increasingly important causes of neurologic disease throughout the world and in the United States. While no US Food and Drug Administration (FDA)-approved therapy is yet available for these infections, prompt recognition and diagnosis from the consulting neurologist will ensure appropriate supportive care for the patient.

\section{INTRODUCTION}

With the spread of West Nile virus across the United States, the evaluation of an acute febrile patient with neurologic abnormalities commonly includes arbovirus infections in the differential. The term arbovirus (arthropod-borne virus) includes several families of viruses that are spread by arthropod vectors, most commonly mosquitoes, ticks, and sand flies. ${ }^{1}$ The families of viruses included in the arbovirus group are Flaviviridae, Togaviridae, Bunyaviridae, and Reoviridae (Table 3-1). These large families of viruses have a common feature, an RNA genome that allows these viruses to rapidly adapt to ever-changing host and environmental conditions. Thus, these virus families are largely responsible for the recent growth in geographic range of emerging viruses such as West Nile virus, dengue virus, and chikungunya virus. This article reviews the epidemiology, presentation, and diagnosis of arbovirus infections and therapeutic approaches to treat them.

\footnotetext{
Address correspondence to Dr J. David Beckham, University of Colorado School of Medicine, Departments of Medicine and Neurology, 12700 East 19th Ave, B168, Aurora, CO 80045, David.beckham@ucdenver.edu.

Unlabeled Use of Products/Investigational Use Disclosure: Drs Beckham and Tyler discuss the unlabeled/investigational use of corticosteroids, humanized monoclonal antibodies, interferon alfa, and IVIg for the treatment of West Nile virus.

Relationship Disclosure: Dr Beckham receives research funding from the National Institute of Allergy and Infectious Diseases and the University of Colorado Neurosciences Institute. Dr Tyler has served on the scientific advisory boards of Biogen; Genentech, Inc; F. Hoffman-La Roche Ltd; and Janssen Pharmaceuticals, Inc; on the data and safety monitoring board of Lpath Incorporated; and as a member of the Progressive Multifocal Leukoencephalopathy Consortium. Dr Tyler has served as associate editor of the Journal of Neuro Virology and Neurology Today and on the editorial boards of Annals of Neurology, Apoptosis, Experimental Neurology, JAMA Neurology, The Journal of Infectious Diseases, Microbial Pathogenesis, and Virology.
} 


\section{FLAVIVIRIDAE}

\section{West Nile Virus}

Most arboviruses maintain an enzootic (animal) cycle that does not involve human infection. West Nile virus is maintained in an enzootic cycle between mosquitos such as Culex pipiens and passerine (perching) bird species such as jays and finches. After an infected mosquito bites a human, the virus replicates in dendritic cells and macrophages in local tissue and lymph nodes, resulting in viremia that eventually disseminates virus to end organs, including the central nervous system (CNS). ${ }^{2}$ Of note, West Nile viremia in humans is not high enough or sustained enough to support subsequent transmission to mosquitoes, so humans are dead-end hosts. The ability of an arbovirus to invade the CNS (neuroinvasiveness) is determined by multiple viral and host factors. ${ }^{3,4}$ Proposed routes of arboviral CNS entry include penetration of the cerebral microvasculature after infection of endothelial cells, diapedesis Unlabeled Use of Products/Investigational Use Disclosure: Drs Beckham and Tyler discuss the unlabeled/investigational use of corticosteroids, humanized monoclonal antibodies, interferon alfa, and IVIg for the treatment of West Nile virus. (movement of infected blood cells across brain capillary walls) of infected leukocytes, passage through the choroid plexus, or passage through fenestrated endothelial cells in the vasculature of specific regions in the CNS. ${ }^{2}$

After crossing the blood-brain barrier, many arboviruses can directly infect and cause death of neurons. ${ }^{5}$ Several studies have shown that apoptosis is an important mechanism of West Nile virus-induced neuron cell death and CNS injury. ${ }^{6-11}$ Immune responses also contribute to clearance of virus but contribute to immune-mediated neuronal cell death as well. ${ }^{12-17}$

West Nile virus infection is now the most common cause of epidemic viral encephalitis in the United States. Since its emergence in New York City in 1999, over 40,000 cases of West Nile virus infection have been reported in the United States, with over 17,000 cases (42\%) of neuroinvasive disease and $1700(4 \%)$ deaths. ${ }^{18}$ The epidemics of West Nile virus in 2003 and 2012 were the largest outbreaks of neuroinvasive viral infections ever reported in the Western Hemisphere. ${ }^{19,20}$

Almost all cases of West Nile virus disease are caused by transmission through a mosquito bite. In most areas of the United States, the majority of cases occur between June and October, reflecting the peak activity period of biting mosquitoes. Occasional cases of West Nile virus disease also occur following transplantation of West Nile virus-infected organs, ${ }^{21}$ breast-feeding, ${ }^{22}$ and blood transfusions from asymptomatic West Nile virus-infected individuals. ${ }^{23}$ Currently, donor organs and blood products are screened for West Nile virus nucleic acids to prevent iatrogenic transmission.

Following transmission of West Nile virus, most infections (approximately 80\%) are asymptomatic. Approximately $20 \%$ of infected individuals develop an acute febrile flulike illness (West Nile fever), characterized by fever, headache, fatigue, anorexia, nausea, myalgia, and lymphadenopathy. A maculopapular rash involving the trunk and limbs occurs in $25 \%$ to $50 \%$ of cases. ${ }^{24}$ Less than $1 \%$ of West Nile virus-infected individuals develop neuroinvasive disease, which can manifest as meningitis, encephalitis, acute flaccid 
paralysis, or a combination of these clinical syndromes. ${ }^{19,25}$ The symptomatology reflects the common predilection for the virus to injure the basal ganglia, thalamus, upper brainstem, and cerebellum as well as the anterior horns of the spinal cord. An estimated 30\% to $40 \%$ of patients with neuroinvasive West Nile virus infection develop meningitis, 50\% to $60 \%$ develop encephalitis, and 5\% to $10 \%$ develop acute flaccid paralysis. ${ }^{26,27}$ Other reported syndromes include chorioretinitis, ${ }^{28}$ myositis, ${ }^{29}$ and autonomic nerve dysfunction. ${ }^{30}$

Neuroinvasive disease most commonly occurs in older individuals (over 60 years of age). In one study, the odds ratio (95\% confidence interval) of developing encephalitis was 2.2 (1.6 to 3.1) in individuals older than 64 years. ${ }^{31}$ Additional identified risk factors for encephalitis include hypertension and diabetes mellitus. ${ }^{31,32}$ Patients who are immunocompromised, including organ transplant recipients, are at high risk of developing severe West Nile virus disease. Specific genetic factors in humans shown to enhance susceptibility to serious West Nile virus disease include single nucleotide polymorphisms in the oligoadenylate synthetase gene, which encodes an interferon-inducible enzyme involved in antiviral innate immunity, ${ }^{33}$ and a genetic deficiency of the chemokine receptor $C C R 5$, which may inhibit trafficking of West Nile virus-specific $\mathrm{CD}^{+}{ }^{+} \mathrm{T}$ cells into the CNS. ${ }^{34}$

West Nile virus meningitis is characterized by the abrupt onset of fever, headache, meningeal signs, photophobia, and phonophobia. Patients have a CSF pleocytosis with an average of 226 cells $/ \mu \mathrm{L}$, mildly elevated protein, and normal glucose. In one study, neutrophils, rather than lymphocytes, were found to predominate in the CSF in approximately $50 \%$ of patients with West Nile virus meningitis. ${ }^{35}$ In some cases of West Nile virus neuroinvasive disease, very atypical-appearing monocytes are noted in the CSF similar to Mollaret cells noted in cases of recurrent meningitis. In cases of West Nile virus meningitis, neuroimaging studies are unremarkable, and the EEG is usually normal.

West Nile virus encephalitis is distinguished from meningitis by the presence of signs and symptoms of brain parenchymal involvement on examination or diagnostic testing including neuroimaging or EEG. Results from multiple studies suggest that patients with West Nile virus encephalitis present with fever (70\% to $100 \%$ ), headache (50\% to $100 \%)$, and altered mental status (45\% to $100 \%)$. ${ }^{36}$ Signs common in West Nile virus encephalitis but unusual in other forms of viral encephalitis include tremor, parkinsonism, and myoclonus (20\% to $40 \%) .26,37$ Weakness is common and may be of a lower motor neuron type associated with hypotonia and areflexia, with preserved sensation. Cranial neuropathies, most commonly involving unilateral or bilateral peripheral facial palsy, occur in approximately $20 \%$.

The prevalence of tremors due to West Nile virus neuroinvasive disease ranges from $12 \%$ to nearly $100 \% .{ }^{38}$ When present, tremors are described as coarse and isolated to the upper extremities and have postural and kinetic components. ${ }^{39}$ Parkinsonian features also occur with variable frequency and include signs of bradykinesia, cogwheel rigidity, hypomimia, and postural instability. ${ }^{38,39}$ Myoclonus can resemble that seen in prion diseases, and usually involves the upper extremities and face. Cerebellar abnormalities including incoordination and gait ataxia occur in a variable percentage of cases. ${ }^{26,37,38}$ 
Patients with West Nile virus infection have a normal complete blood count or mild leukocytosis. ${ }^{1}$ The CSF findings in patients with West Nile virus encephalitis are almost identical to the findings with meningitis, including pleocytosis (mean 227 cells $/ \mu \mathrm{L}$ ), elevated protein, and normal glucose. Neutrophils predominate rather than lymphocytes in $37 \%$ of cases (Case 3-1). ${ }^{35}$ MRI is abnormal in approximately $50 \%$ to $70 \%$ of West Nile virus encephalitis cases, with the frequency of positive MRI findings increasing with imaging later in the course of disease (more than 7 days after symptom onset) and increased sensitivity with use of T2-weighted fast spin echo and fluid-attenuated inversion recovery (FLAIR) sequences. When present, MRI abnormalities typically involve the thalamus, basal ganglia, and brainstem (Figure 3-1). CT is considerably less sensitive than MRI and is usually normal.

\section{Case 3-1}

A 64-year-old woman who lived in western Nebraska was brought to the emergency department in August by her family for increasing confusion and altered mental status. The patient's husband stated that the patient was in her usual state of good health until she developed fever and fatigue 3 days prior to presentation. Over the next 2 days, she developed nausea, vomiting, and diarrhea associated with increasing headache. The morning of presentation, the patient was confused and unable to respond to questions. On examination, she was febrile $\left(39.2^{\circ} \mathrm{C}\left[102.5^{\circ} \mathrm{F}\right]\right)$, and awake but unable to follow commands or respond purposefully. Her breathing was rapid, shallow, and labored. In the emergency department, the patient was intubated, blood cultures were obtained, CT of the head was negative, and a lumbar puncture was performed. Lumbar puncture showed an opening pressure of $15 \mathrm{~cm}$ water, a CSF pleocytosis of 620 cells $/ \mu \mathrm{L}$ (55\% neutrophils, $40 \%$ lymphocytes), glucose concentration of $42 \mathrm{mg} / \mathrm{dL}$, and protein concentration of 114 $\mathrm{mg} / \mathrm{dL}$. The CSF Gram stain was negative, as were the CSF culture and blood cultures. MRI of the brain showed T2-signal hyperintensity in the thalamus (bilaterally), midbrain, basal ganglia, and left medial temporal lobe (Figure 3-1). CSF testing for West Nile virus IgM was positive. Her hospital course was complicated by cardiac arrest and progressive loss of response to stimuli. The patient died on hospital day 14 .
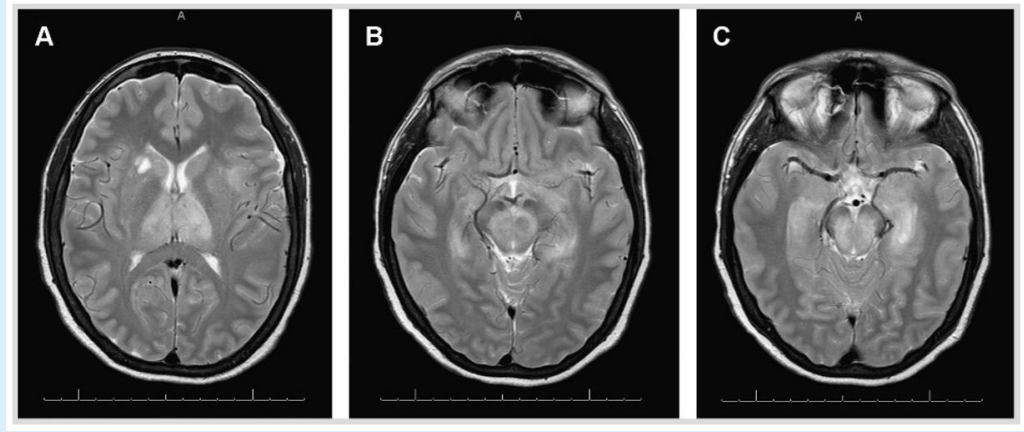

FIGURE 3-1.

Axial T2-weighted fast spin echo MRI of a patient with West Nile virus encephalitis. Increased signal intensity in the thalamus bilaterally and in the right caudate nucleus $(A)$, the substantia nigra $(B)$, and the midbrain and left medial temporal lobe $(C)$. 


\section{Comment}

The presentation of acute altered mental status in an otherwise healthy individual is concerning for severe encephalitis or severe bacterial meningitis. In cases such as this, the goal is to initiate therapy for acute bacterial meningitis and herpes simplex encephalitis as soon as possible. Lumbar puncture is the key diagnostic test. In this case, the CSF exhibited a neutrophil pleocytosis that is more commonly found in bacterial meningitis but can be found in up to $50 \%$ of West Nile virus neuroinvasive cases. The subsequent MRI findings are characteristic of West Nile virus. In particular, involvement of deep gray matter in regions such as the basal ganglia, thalamus, and brainstem are characteristic of central nervous system infection by a Flavivirus such as West Nile virus. Advanced age and intubation are predictors of poor outcome in patients with neuroinvasive West Nile virus infection.

West Nile virus can also cause a poliomyelitislike acute flaccid paralysis that results from viral injury to motor neurons in the anterior horns of the spinal cord. ${ }^{40}$ Patients typically develop acute onset of asymmetric limb paralysis associated with decreased or absent reflexes and preserved sensation. Weakness may be associated with respiratory impairment from diaphragm or intercostal muscle paralysis. Electrophysiology studies obtained acutely show reduction in amplitude or absence of compound muscle action potentials with relatively preserved sensory nerve action potentials. EMG studies obtained 2 to 3 weeks after onset show characteristic features of denervation, including increased insertional activity and fasciculations. In contrast to Guillain-Barré syndrome, no evidence of significant demyelination (slowed conduction velocities or conduction block) is seen. In most, but not all, cases of West Nile virus, acute flaccid paralysis is associated with clinical signs and symptoms of systemic infection, and the syndrome may occur in association with meningitis or encephalitis. Patients typically have CSF features similar to the features seen in meningoencephalitis. MRI of the spinal cord may show increased signal in the anterior horns on T2 and FLAIR sequences.

West Nile virus neuroinvasive disease is usually diagnosed by demonstration of West Nile virus-specific IgM in CSF by enzyme-linked immunosorbent assay (ELISA). ${ }^{41}$ In some patients, CSF West Nile virus IgM may persist for 1 year or longer, and it may be necessary to perform serial studies of serum and CSF IgG and IgM to definitively distinguish acute from remote infection. CSF polymerase chain reaction (PCR) for West Nile virus is highly specific, but less sensitive than serologic studies. CSF PCR may be particularly useful early in infection, before antibody responses have fully evolved, and in immunocompromised individuals who may have delayed or absent seroconversion. ${ }^{41}$ Antibodies reacting with West Nile virus antigens in ELISA tests may occur as a result of heterologous crossreactions induced by infection with or vaccination against other flaviviruses, including $\mathrm{St}$ Louis encephalitis virus, yellow fever virus, and Japanese encephalitis virus. In some cases, it may be necessary to confirm ELISA results by plaque-reduction neutralization assays. Neutralization antibody titers are typically highest against the inciting virus compared with cross-reacting species. 
No specific therapy of proven benefit for West Nile virus infection exists. Isolated case reports and small series describe both benefit and lack of effect from treatment with IVIg containing high-titer anti-West Nile virus antibodies and with interferon alfa. A multicenter randomized controlled trial of a high-titer anti-West Nile virus IVIg preparation was conducted by the Collaborative Antiviral Study Group (CASG) and did not show evidence of a therapeutic benefit. ${ }^{42}$ A phase $2 / 3$ trial to evaluate the safety and efficacy of a humanized monoclonal antibody directed against an epitope on the West Nile virus envelope glycoprotein was closed because of low enrollment (NCT00515385). Isolated reports of use of corticosteroids in patients with West Nile virus acute flaccid paralysis and brainstem disease do not permit any conclusions about efficacy. ${ }^{43}$

Mortality from West Nile virus neuro-invasive disease is approximately $12 \%$ and occurs almost exclusively in the subsets of patients with severe encephalitis or severe acute flaccid paralysis. The frequency and severity of sequelae are still not well understood. ${ }^{44}$ Six months after the acute infection, $40 \%$ of patients with movement disorders such as myoclonus, parkinsonism, or tremors have residual symptoms, and 20\% have ongoing symptoms at 18 months of follow-up. ${ }^{44}$ Up to $50 \%$ of West Nile virus encephalitis survivors report cognitive problems, decreased motor speed, and diminished dexterity 3 months after the initial infection. ${ }^{44}$

\section{Other Flaviviridae}

According to the World Health Organization (WHO), dengue virus causes approximately 50 million cases of disease annually throughout the world and continues to expand its geographic distribution throughout tropical and subtropical regions. Dengue virus isolates are divided into four different serotypes and are maintained in endemic cycles between humans and the Aedes aegypti mosquito. Dengue virus infection causes an acute self-limited febrile syndrome characterized by headache, retroorbital pain, rash, nausea, vomiting, diarrhea, myalgia, and arthralgia. In individuals with prior exposure to dengue virus, reexposure to another serotype places the individual at increased risk for dengue hemorrhagic fever, characterized by increased vascular permeability, thrombocytopenia, hypotension, and hemorrhagic manifestations.

Acute dengue virus infections are rarely associated with CNS involvement, and direct dengue virus infection of the nervous system remains controversial. ${ }^{45}$ A 2014 study in India and Nepal found that $9.2 \%$ of dengue infections were associated with a neurologic complication. ${ }^{45}$ Of the 45 patients in a prospective cohort study with neurologic manifestations associated with dengue virus infection, encephalitis was the most common presentation at $33 \% .{ }^{45}$ Other associated neurologic abnormalities include encephalopathy (22\%), myelitis, Guillain-Barré syndrome, myositis, and neuralgic amyotrophy. ${ }^{45}$ The diagnosis of dengue is often clinical in endemic locations. Diagnosis can be supported with serology using acute and convalescent serum for antibody to the dengue virus envelope protein. No known therapy exists for acute dengue virus infection. Among other problems, the development of dengue hemorrhagic fever with recurrent infection from new serotypes has hampered the development of efficacious vaccination strategies. 
Powassan virus is a rare tick-borne flavivirus maintained in an enzootic cycle between Ixodes ticks and small mammals. ${ }^{46}$ Powassan virus causes rare sporadic cases of neurologic disease in humans. In the United States, Powassan virus has been reported in the northeastern and north central states. ${ }^{46}$ Symptoms of infection vary from mild fever and myalgia to acute flaccid paralysis, encephalitis, and death. ${ }^{46,47}$

St Louis encephalitis virus is another member of the Flaviviridae family, spread by mosquito vectors in southern Midwest states. Cases of St Louis encephalitis have rapidly decreased with the expansion of West Nile virus. According to Centers for Disease Control and Prevention (CDC) data, two cases of neuroinvasive St Louis encephalitis were reported in the District of Columbia in 2010. St Louis encephalitis causes neuroinvasive disease in a minority of patients, with very similar clinical patterns compared to West Nile virus.

\section{TOGAVIRIDAE (ALPHAVIRUSES)}

The family Togaviridae is composed of enveloped single-stranded positive-sense RNA viruses. In North America, eastern equine encephalitis virus is the most important member of this group causing encephalitis and is, fortunately, rare. Chikungunya virus has recently emerged as the cause of massive epidemics of a febrile arthralgic illness that, in rare cases, is associated with neurologic manifestations. However, since some epidemics can involve millions of infected cases, even low-incidence involvement of the nervous system can result in significant numbers of affected individuals.

\section{Eastern Equine Encephalitis Virus}

Eastern equine encephalitis virus is an alphavirus that causes a sporadic mosquito-borne viral infection endemic in the eastern United States and Caribbean. Four lineages of eastern equine encephalitis virus exist; group I causes most disease in humans, whereas groups IIA, IIB, and III cause primarily equine disease in Central America and South America. ${ }^{48-50}$ Eastern equine encephalitis virus is maintained in an enzootic cycle with avian species after a bite from a mosquito vector, Culiseta melanura. ${ }^{49}$ Birds serve as the primary reservoir hosts and amplifying hosts, and humans are incidentally infected by various mosquito bridging vectors, including Culex, Culiseta, and Aedes species. ${ }^{51}$ In the United States, most cases are along the eastern seaboard, and cases are found sporadically along the Gulf Coast, typically within 5 miles of swamplands or marshlands. Approximately 1 in 30 individuals exposed to eastern equine encephalitis virus develops disease..$^{52}$ Eastern equine encephalitis virus causes sporadic infections in human populations during the summer months and occasional larger epidemic outbreaks.

Patients infected with eastern equine encephalitis virus develop nonspecific symptoms common to other causes of viral encephalitis, including fever, chills, malaise, and myalgia. The prodrome is followed by either recovery without neurologic illness or the onset of encephalitis characterized by severe headache, confusion, nausea, and vomiting. Seizures, focal neurologic deficits such as cranial nerve palsies or focal weakness, and meningismus are common findings. ${ }^{53}$ Brainstem involvement is common and is associated with gaze palsies, nystagmus, and pupillary abnormalities. Mortality is about $33 \%$ but increases to 
$50 \%$ in patients older than 60 years of age. Moderate to severe sequelae occur in one-third of survivors. ${ }^{53}$

Similar to the flaviviruses above, MRI abnormalities occur predominantly in the thalamus, basal ganglia, and brainstem. ${ }^{53}$ EEG is typically diffusely slow, with some severely ill patients having burst suppression or diffuse high-voltage delta-wave slowing. ${ }^{54}$ Laboratory studies may show a peripheral leukocytosis with a neutrophil predominance in $69 \%$ and hyponatremia in $60 \%$ of patients. ${ }^{53} \mathrm{CSF}$ typically shows a significant pleocytosis with a mean cell count of 370 leukocytes $/ \mu \mathrm{L}$ in one study ${ }^{53}$ and 940 leukocytes $/ \mu \mathrm{L}$ in another. ${ }^{54}$ Approximately $60 \%$ of eastern equine encephalitis virus cases will display a neutrophil predominance in the CSF with a median neutrophil proportion of $70 \%$ of nucleated cells. ${ }^{53,54}$ CSF protein is often elevated (median $97 \mathrm{mg} / \mathrm{dL}$ ), and $90 \%$ of patients have CSF glucose concentrations less than $60 \%$ of coincident serum values. CSF red blood cells are common, reflecting the necrotic and hemorrhagic features of the encephalitis pathologically.

Diagnosis is typically made by demonstration of IgM antibodies in CSF by capture ELISA, demonstration of serum IgM antibodies, or a fourfold increase in IgG antibodies between acute and convalescent sera. No proven antiviral therapy exists for eastern equine encephalitis virus, and treatment is focused on supportive care and managing complications such as seizures and increased intracranial pressure. No commercial vaccine for eastern equine encephalitis virus exists, but standard precautions to prevent mosquito bites may help to prevent infection. In evaluating laboratory and imaging studies for prognostic value, one study found that CSF leukocytosis greater than 500 cells $/ \mu \mathrm{L}$ and hyponatremia less than 130 $\mathrm{mEq} / \mathrm{L}$ were predictive of a poor outcome, ${ }^{53}$ but a longer prodromal period was associated with a better prognosis. Sequelae may be more common and generally more severe in children. ${ }^{53}$

\section{Venezuelan Equine Encephalitis Virus}

Venezuelan equine encephalitis virus is an Alphavirus that was originally isolated from the brains of dead horses. ${ }^{55}$ Venezuelan equine encephalitis virus circulates between a mosquito vector, Culex melanoconion, and forest-dwelling small mammals and birds in Central America and South America. It emerges during epizootic outbreaks to infect horses and humans via bridge vectors such as Aedes taeniorhynchus. Epidemics typically occur in northern South America, but have extended as far north as Mexico and Texas. ${ }^{56}$ In areas of sylvatic (forest) activity, human seroprevalence can be 50\%. In contrast to many encephalitic arbovirus infections, Venezuelan equine encephalitis viremia in humans is sufficient to transmit virus to mosquitos for approximately 72 hours. ${ }^{57}$ However, humans are not likely to play an important role in spread; instead, epizootic strains of Venezuelan equine encephalitis virus are dependent on equine amplification for epidemic spread. Forty percent of patients with Venezuelan equine encephalitis virus have virus in the pharynx, suggesting that direct spread between humans may be possible, although human-to-human spread has never been proven. ${ }^{58}$

Symptomatic Venezuelan equine encephalitis virus infection results in neurologic disease in a minority of cases following a viral prodrome of fever, headache, photophobia, conjunctival injection, myalgia, arthralgia, nausea, and dizziness. Pharyngeal inflammation, painful 
cervical lymphadenopathy, somnolence, and tremulousness may occur. ${ }^{59} \mathrm{CSF}$ analysis reveals lymphocytic pleocytosis, elevated protein, and a normal CSF glucose. Few reports of neuroimaging studies exist. CT scans are usually normal. EEG typically shows diffuse slowing, although some cases have focal temporal slowing similar to that seen in herpes simplex virus encephalitis.

Venezuelan equine encephalitis virus infection is diagnosed by detection of specific $\operatorname{IgM}$ antibody in the CSF or serum, and fatality rates range from $0.2 \%$ to $1 \%$ of symptomatic Venezuelan equine virus-infected patients without symptoms of encephalitis and increases to $10 \%$ to $25 \%$ in patients with encephalitis. No antiviral therapy or human vaccine has shown proven benefit.

\section{Chikungunya Virus}

Recently, an emerging alphavirus called chikungunya virus has rapidly spread across the tropical and subtropical regions around the globe. The name "chikungunya" is derived from the Makonde language of Tanzania and means "that which bends up." Over 1 million cases of chikungunya virus disease were reported in recent epidemics in India. ${ }^{60}$ The virus rapidly spread west and now is endemic in the Caribbean islands, South America, Central America, and recently the southeastern United States. ${ }^{61,62}$ Chikungunya virus has rapidly adapted to multiple mosquito-mammal transmission cycles depending on the geographic region. ${ }^{63} \mathrm{An}$ urban cycle between the mosquito vector, A. aegypti, and humans is thought to support much of the recent epidemic spread. Following the bite of an infected mosquito, chikungunya virus causes a characteristic febrile syndrome manifested by headache, rash, and severe arthralgia. Patients can develop a poly-articular large-joint arthritis during acute infection, and symptoms of joint pain can linger for months following infection.

Chikungunya virus infection of the CNS is rare but has been reported. Associated neurologic clinical manifestations of chikungunya virus have included meningitis, encephalitis, and encephalomyeloradiculitis. ${ }^{64-66}$ Diagnosis of chikungunya virus infection can be made with serology using acute and convalescent serum, and cases of chikungunya virus-associated CNS disease have been confirmed following detection of anti-chikungunya virus IgM in the CSF. ${ }^{67}$ No known efficacious therapy or vaccine exists for chikungunya virus.

\section{BUNYAVIRIDAE}

\section{California Encephalitis Group}

California encephalitis virus, La Crosse virus, Jamestown Canyon virus, and Tahyna virus are the major causes of encephalitis in the California encephalitis group within the family of Bunyaviridae and genus Bunyavirus. Of these viruses, La Crosse virus, California encephalitis virus, and Jamestown Canyon virus are causes of disease in the United States, and Tahyna virus is predominantly a cause of encephalitis in Russia. La Crosse virus is the most common cause of disease in the California encephalitis group. It was originally described in 1965 after a postmortem examination of a child who died of encephalitis in La Crosse, Wisconsin. ${ }^{68} \mathrm{La}$ Crosse virus is transmitted in an enzootic pattern between squirrels and chipmunks by the mosquito Aedes triseriatus in areas of the Mississippi and Ohio River 
basins. ${ }^{69}$ Recent outbreaks of La Crosse virus have demonstrated a shift in incidence to the Appalachian region and West Virginia. ${ }^{70}$ Human exposure is often associated with camping or other recreational activities in wooded areas in endemic regions.

California encephalitis virus was originally isolated in 1941, but it is rare. Most human cases occur in the western United States and Canada. The ratio of asymptomatic to symptomatic infections is $1000: 1 .^{71}$

Although La Crosse and California encephalitis viruses mostly cause disease in children, with a mean age of La Crosse virus infection in children of 7.5 years, Jamestown Canyon virus affects predominantly elderly individuals in regions of the northern United States, with seroprevalence in some areas reaching $10 \%{ }^{72} \mathrm{~A}$ recent report of a Jamestown Canyon virus infection in Montana underscores continued low-level transmission in the northern continental United States. ${ }^{73}$

Symptoms of La Crosse virus encephalitis include fever, headache, vomiting in $70 \%$, seizures in $46 \%$, and altered mental status in $42 \%$ of cases. ${ }^{71}$ Focal neurologic signs include hemiparesis, aphasia, dysarthria, and chorea. About $10 \%$ of patients develop increased intracranial pressure, and, rarely, cerebral herniation can occur. ${ }^{71}$ Jamestown Canyon virus has similar clinical features.

CSF analysis for the California encephalitis virus group reveals a lymphocytic pleocytosis of approximately 600 cells/ $\mu \mathrm{L}$ and normal glucose. An increased CSF protein is found in $30 \%$ of patients with encephalitis. ${ }^{71}$ Peripheral leukocytosis and hyponatremia secondary to syndrome of inappropriate secretion of antidiuretic hormone (SIADH) are common. IgM detection in the CSF or a fourfold increase in paired sera for IgG is considered diagnostic for infection.

No antiviral therapy currently exists for the California encephalitis group of viruses, and no vaccine is available. Mortality from La Crosse encephalitis is approximately $1 \%$ to $3 \%$, and most survivors return to normal function. Ribavirin treatment for La Crosse encephalitis in children is not recommended because of problems with pharmacokinetics, toxicity at higher doses, and penetration into the CNS. ${ }^{74}$

\section{CONCLUSION}

Arbovirus infections are increasingly common throughout the United States and the world. Cases of arbovirus infections will continue to challenge physicians to match the constellation of findings on examination, laboratory studies, and neuroimaging with likely viral causes. Thus, it is important to understand the characteristic presentations of arbovirus infections so the appropriate testing can be completed and patients can be provided with the specific prognostic information for a specific virologic diagnosis. Although no approved therapies exist for arbovirus infections, the diagnostic and prognostic information provided by these investigations can be very important for patients and families. 


\section{Acknowledgments}

Dr Tyler has received research support from the National Multiple Sclerosis Society, the National Institute of Allergy and Infectious Diseases, the National Institute of Neurological Disorders and Stroke, and the US Department of Veterans Affairs Merit Program and receives royalties from Elsevier B.V. and McGraw-Hill Education.

\section{References}

1. Davis LE, Beckham JD, Tyler KL. North American encephalitic arboviruses. Neurol Clin. 2008; 26(3):727-757. ix. DOI: 10.1016/j.ncl.2008.03.012 [PubMed: 18657724]

2. Petersen LR, Brault AC, Nasci RS. West Nile virus: review of the literature. JAMA. 2013; 310(3): 308-315. DOI: 10.1001/jama.2013.8042 [PubMed: 23860989]

3. Wang P, Bai F, Zenewicz LA, et al. IL-22 signaling contributes to West Nile encephalitis pathogenesis. PLoS One. 2012; 7(8):e44153.doi: 10.1371/journal.pone.0044153 [PubMed: 22952908]

4. Dai J, Wang P, Bai F, et al. Icam-1 participates in the entry of west nile virus into the central nervous system. J Virol. 2008; 82(8):4164-4168. DOI: 10.1128/JVI.02621-07 [PubMed: 18256150]

5. Samuel MA, Morrey JD, Diamond MS. Caspase 3-dependent cell death of neurons contributes to the pathogenesis of West Nile virus encephalitis. J Virol. 2007; 81(6):2614-2623. DOI: 10.1128/ JVI.02311-06 [PubMed: 17192305]

6. Melian EB, Edmonds JH, Nagasaki TK, et al. West Nile virus NS2A protein facilitates virusinduced apoptosis independently of interferon response. J Gen Virol. 2013; 94(pt 2):308-313. DOI: 10.1099/vir.0.047076-0 [PubMed: 23114626]

7. Yang MR, Lee SR, Oh W, et al. West Nile virus capsid protein induces p53-mediated apoptosis via the sequestration of HDM2 to the nucleolus. Cell Microbiol. 2008; 10(1):165-176. DOI: 10.1111/j. 1462-5822.2007.01027.x [PubMed: 17697133]

8. Medigeshi GR, Lancaster AM, Hirsch AJ, et al. West Nile virus infection activates the unfolded protein response, leading to CHOP induction and apoptosis. J Virol. 2007; 81(20):10849-10860. DOI: 10.1128/JVI.01151-0 [PubMed: 17686866]

9. Kleinschmidt MC, Michaelis M, Ogbomo H, et al. Inhibition of apoptosis prevents West Nile virus induced cell death. BMC Microbiol. 2007; 7:49.doi: 10.1186/1471-2180-7-49 [PubMed: 17535425]

10. Parquet MC, Kumatori A, Hasebe F, et al. West Nile virus-induced bax-dependent apoptosis. FEBS Lett. 2001; 500(1-2):17-24. DOI: 10.1016/S0014-5793(01)02573-X [PubMed: 11434919]

11. Beatman E, Oyer R, Shives KD, et al. West Nile virus growth is independent of autophagy activation. Virology. 2012; 433(1):262-272. DOI: 10.1016/j.virol.2012.08.016 [PubMed: 22939285]

12. Samuel MA, Whitby K, Keller BC, et al. PKR and RNase L contribute to protection against lethal West Nile Virus infection by controlling early viral spread in the periphery and replication in neurons. J Virol. 2006; 80(14):7009-7019. DOI: 10.1128/JVI.00489-06 [PubMed: 16809306]

13. Sitati EM, Diamond MS. CD4+ T-cell responses are required for clearance of West Nile virus from the central nervous system. J Virol. 2006; 80(24):12060-12069. DOI: 10.1128/JVI.01650-06 [PubMed: 17035323]

14. Suthar MS, Ma DY, Thomas S, et al. IPS-1 is essential for the control of West Nile virus infection and immunity. PLoS Pathog. 2010; 6(2):e1000757.doi: 10.1371/journal.ppat.1000757 [PubMed: 20140199]

15. Thompson BS, Moesker B, Smit JM, et al. A therapeutic antibody against west nile virus neutralizes infection by blocking fusion within endosomes. PLoS Pathog. 2009; 5(5):e1000453.doi: 10.1371/journal.ppat.1000453 [PubMed: 19478866]

16. Zhang B, Chan YK, Lu B, et al. CXCR3 mediates region-specific antiviral T cell trafficking within the central nervous system during West Nile virus encephalitis. J Immunol. 2008; 180(4):26412649. DOI: 10.4049/jimmunol.180.4.2641 [PubMed: 18250476] 
17. Clarke P, Leser JS, Quick ED, et al. Death receptor-mediated apoptotic signaling is activated in the brain following infection with West Nile virus in the absence of a peripheral immune response. J Virol. 2014; 88(2):1080-1089. DOI: 10.1128/JVI.02944-13 [PubMed: 24198425]

18. Centers for Disease Control and Prevention. [Accessed October 2, 2015] West Nile virus. www.cdc.gov/westnile/index.html. Updated February 12, 2015

19. Kramer LD, Li J, Shi PY. West Nile virus. Lancet Neurol. 2007; 6(2):171-181. DOI: 10.1016/ S1474-4422(07)70030-3 [PubMed: 17239804]

20. Racsa L, Gander R, Chung W, et al. Clinical features of West Nile virus epidemic in Dallas, Texas, 2012. Diagn Microbiol Infect Dis. 2014; 78(2):132-136. DOI: 10.1016/j.diagmicrobio. 2013.11.006 [PubMed: 24316017]

21. Iwamoto M, Jernigan DB, Guasch A, et al. Transmission of West Nile virus from an organ donor to four transplant recipients. N Engl J Med. 2003; 348(22):2196-2203. DOI: 10.1056/ NEJMoa022987 [PubMed: 12773646]

22. Centers for Disease Control and Prevention (CDC). Possible West Nile virus transmission to an infant through breast-feeding-Michigan, 2002. MMWR Morb Mortal Wkly Rep. 2002; 51(39): 877-878. [PubMed: 12375687]

23. Biggerstaff BJ, Petersen LR. Estimated risk of West Nile virus transmission through blood transfusion during an epidemic in Queens, New York City. Transfusion. 2002; 42(8):1019-1026. DOI: 10.1046/j.1537-2995.2002.00167.x [PubMed: 12385413]

24. Watson JT, Pertel PE, Jones RC, et al. Clinical characteristics and functional outcomes of West Nile Fever. Ann Intern Med. 2004; 141(5):360-365. DOI: 10.7326/0003-4819-141-5-200409070-00010 [PubMed: 15353427]

25. Bode AV, Sejvar JJ, Pape WJ, et al. West Nile virus disease: a descriptive study of 228 patients hospitalized in a 4-county region of Colorado in 2003. Clin Infect Dis. 2006; 42(9):1234-1240. DOI: $10.1086 / 503038$ [PubMed: 16586381]

26. Sejvar JJ, Haddad MB, Tierney BC, et al. Neurologic manifestations and outcome of West Nile virus infection. JAMA. 2003; 290(4):511-515. DOI: 10.1001/jama.290.4.511 [PubMed: 12876094]

27. Sejvar JJ, Leis AA, Stokic DS, et al. Acute flaccid paralysis and West Nile virus infection. Emerg Infect Dis. 2003; 9(7):788-793. DOI: 10.3201/eid0907.030129 [PubMed: 12890318]

28. Bains HS, Jampol LM, Caughron MC, Parnell JR. Vitritis and chorioretinitis in a patient with West Nile virus infection. Arch Ophthalmol. 2003; 121(2):205-207. DOI: 10.1001/archopht.121.2.205 [PubMed: 12583786]

29. Smith RD, Konoplev S, DeCourten-Myers G, Brown T. West Nile virus encephalitis with myositis and orchitis. Hum Pathol. 2004; 35(2):254-258. DOI: 10.1016/j.humpath.2003.09.007 [PubMed: 14991545]

30. Fratkin JD, Leis AA, Stokic DS, et al. Spinal cord neuropathology in human West Nile virus infection. Arch Pathol Lab Med. 2004; 128(5):533-537. [PubMed: 15086282]

31. Jean CM, Honarmand S, Louie JK, Glaser CA. Risk factors for West Nile virus neuroinvasive disease, California, 2005. Emerg Infect Dis. 2007; 13(12):1918-1920. DOI: 10.3201/ eid1312.061265 [PubMed: 18258047]

32. Nash D, Mostashari F, Fine A, et al. The outbreak of West Nile virus infection in the New York City area in 1999. N Engl J Med. 2001; 344(24):1807-1814. DOI: 10.1056/ NEJM200106143442401 [PubMed: 11407341]

33. Yakub I, Lillibridge KM, Moran A, et al. Single nucleotide polymorphisms in genes for $2^{\prime}-5^{\prime}$ oligoadenylate synthetase and RNase L in patients hospitalized with West Nile virus infection. J Infect Dis. 2005; 192(10):1741-1748. DOI: 10.1086/497340 [PubMed: 16235172]

34. Lim JK, Louie CY, Glaser C, et al. Genetic deficiency of chemokine receptor CCR5 is a strong risk factor for symptomatic West Nile virus infection: a meta-analysis of 4 cohorts in the US epidemic. J Infect Dis. 2008; 197(2):262-265. DOI: 10.1086/524691 [PubMed: 18179388]

35. Tyler KL, Pape J, Goody RJ, et al. CSF findings in 250 patients with serologically confirmed West Nile virus meningitis and encephalitis. Neurology. 2006; 66(3):361-365. DOI: 10.1212/01.wnl. 0000195890.70898.1f [PubMed: 16382032] 
36. Beckham JD, Tyler KL. Neuro-intensive care of patients with acute CNS infections. Neurotherapeutics. 2012; 9(1):124-138. DOI: 10.1007/s13311-011-0086-5 [PubMed: 22102180]

37. Debiasi RL, Tyler KL. West Nile virus meningoencephalitis. Nat Clin Pract Neurol. 2006; 2(5): 264-275. DOI: 10.1038/ncpneuro0176 [PubMed: 16932563]

38. Davis LE, DeBiasi R, Goade DE, et al. West Nile virus neuroinvasive disease. Ann Neurol. 2006; 60(3):286-300. DOI: 10.1002/ana.20959 [PubMed: 16983682]

39. Sejvar JJ, Marfin AA. Manifestations of West Nile neuroinvasive disease. Rev Med Virol. 2006; 16(4):209-224. DOI: 10.1002/rmv.501 [PubMed: 16906589]

40. Sejvar JJ. West Nile virus and “poliomyelitis”. Neurology. 2004; 63(2):206-207. DOI: 10.1212/01.WNL.0000130361.62281.69 [PubMed: 15277609]

41. Shi PY, Wong SJ. Serologic diagnosis of West Nile virus infection. Expert Rev Mol Diagn. 2003; 3(6):733-741. DOI: 10.1586/14737159.3.6.733 [PubMed: 14628901]

42. Hart J Jr, Tillman G, Kraut MA, et al. West Nile virus neuroinvasive disease: neurological manifestations and prospective longitudinal outcomes. BMC Infect Dis. 2014; 14:248.doi: 10.1186/1471-2334-14-248 [PubMed: 24884681]

43. Pyrgos V, Younus F. High-dose steroids in the management of acute flaccid paralysis due to West Nile virus infection. Scand J Infect Dis. 2004; 36(6-7):509-512. DOI: 10.1080/00365540410020659 [PubMed: 15307586]

44. Sejvar JJ. The long-term outcomes of human West Nile virus infection. Clin Infect Dis. 2007; 44(12):1617-1624. DOI: 10.1086/518281 [PubMed: 17516407]

45. Sahu R, Verma R, Jain A, et al. Neurologic complications in dengue virus infection: a prospective cohort study. Neurology. 2014; 83(18):1601-1609. DOI: 10.1212/WNL.0000000000000935 [PubMed: 25253749]

46. Sung S, Wurcel AG, Whittier S, et al. Powassan meningoencephalitis, New York, New York, USA. Emerg Infect Dis. 2013; 19(9)doi: 10.3201/eid1909.121846

47. Tavakoli NP, Wang H, Dupuis M, et al. Fatal case of deer tick virus encephalitis. N Engl J Med. 2009; 360(20):2099-2107. DOI: 10.1056/NEJMoa0806326 [PubMed: 19439744]

48. Centers for Disease Control and Prevention (CDC). Eastern equine encephalitis-New Hampshire and Massachusetts, August-September 2005. MMWR Morb Mortal Wkly Rep. 2006; 55(25):697_ 700. [PubMed: 16810146]

49. Loftin KC, Diallo AA, Herbert MW, et al. Five-year surveillance of West Nile and eastern equine encephalitis viruses in Southeastern Virginia. J Environ Health. 2006; 68(9):33-40. [PubMed: 16696451]

50. Unnasch RS, Sprenger T, Katholi CR, et al. A dynamic transmission model of eastern equine encephalitis virus. Ecol Modell. 2006; 192(3-4):425-440. DOI: 10.1016/j.ecolmodel.2005.07.011 [PubMed: 16501661]

51. Mitchell CJ, Niebylski ML, Smith GC, et al. Isolation of eastern equine encephalitis virus from Aedes albopictus in Florida. Science. 1992; 257(5069):526-527. DOI: 10.1126/science.1321985 [PubMed: 1321985]

52. Goldfield M, Taylor BF, Welsh JN, et al. The persistence of eastern encephalitis serologic reactivity following overt and inapparent human infection—an eight year follow-up. Am J Epidemiol. 1968; 87(1):50-57. [PubMed: 5640315]

53. Deresiewicz RL, Thaler SJ, Hsu L, Zamani AA. Clinical and neuroradiographic manifestations of eastern equine encephalitis. N Engl J Med. 1997; 336(26):1867-1874. [PubMed: 9197215]

54. Przelomski MM, O'Rourke E, Grady GF, et al. Eastern equine encephalitis in Massachusetts: a report of 16 cases, 1970-1984. Neurology. 1988; 38(5):736-739. [PubMed: 3362371]

55. Beck CE, Wyckoff RW. Venezuelan equine encephalomyelitis. Science. 1938; 88(2292):530.

56. Griffin DE, Levine B, Tyor WR, Irani DN. The immune response in viral encephalitis. Semin Immunol. 1992; 4(2):111-119. [PubMed: 1319767]

57. Wang E, Bowen RA, Medina G, et al. Virulence and viremia characteristics of 1992 epizootic subtype IC Venezuelan equine encephalitis viruses and closely related enzootic subtype ID strains. Am J Trop Med Hyg. 2001; 65(1):64-69. [PubMed: 11504410] 
58. Weaver SC, Salas R, Rico-Hesse R, et al. Re-emergence of epidemic Venezuelan equine encephalomyelitis in South America. VEE Study Group. Lancet. 1996; 348(9025):436-440. DOI: 10.1016/S0140-6736(96)02275-1 [PubMed: 8709783]

59. Molina OM, Morales MC, Soto ID, et al. Venezuelan equine encephalitis. 1995 outbreak: clinical profile of the case with neurologic involvement. Rev Neurol. 1999; 29(2):296-298. [PubMed: 10797912]

60. Pialoux G, Gauzere BA, Jaureguiberry S, Strobel M. Chikungunya, an epidemic arbovirosis. Lancet Infect Dis. 2007; 7(5):319-327. DOI: 10.1016/S1473-3099(07)70107-X [PubMed: 17448935]

61. Prince HE, Seaton BL, Matud JL, Batterman HJ. Chikungunya virus RNA and antibody testing at a national reference laboratory since the emergence of Chikungunya in the Americas. Clin Vaccine Immunol. 2015; 22(3):291-297. DOI: 10.1128/CVI.00720-14 [PubMed: 25540275]

62. Lindsey NP, Prince HE, Kosoy O, et al. Chikungunya virus infections among travelers-United States, 2010-2013. Am J Trop Med Hyg. 2015; 92(1):82-87. DOI: 10.4269/ajtmh.14-0442 [PubMed: 25349374]

63. Tsetsarkin KA, Weaver SC. Sequential adaptive mutations enhance efficient vector switching by Chikungunya virus and its epidemic emergence. PLoS Pathog. 2011; 7(12):e1002412.doi: 10.1371/journal.ppat.1002412 [PubMed: 22174678]

64. Nelson J, Waggoner JJ, Sahoo MK, et al. Encephalitis caused by Chikungunya virus in a traveler from the Kingdom of Tonga. J Clin Microbiol. 2014; 52(9):3459-3461. DOI: 10.1128/JCM. 01288-14 [PubMed: 24958800]

65. Chusri S, Siripaitoon P, Hirunpat S, Silpapojakul K. Case reports of neuro-Chikungunya in southern Thailand. Am J Trop Med Hyg. 2011; 85(2):386-389. DOI: 10.4269/ajtmh.2011.10-0725 [PubMed: 21813863]

66. Ganesan K, Diwan A, Shankar SK, et al. Chikungunya encephalomyeloradiculitis: report of 2 cases with neuroimaging and 1 case with autopsy findings. AJNR Am J Neuroradiol. 2008; 29(9):16361637. DOI: 10.3174/ajnr.A1133 [PubMed: 18566010]

67. Robin S, Ramful D, Le Seach' F, et al. Neurologic manifestations of pediatric chikungunya infection. J Child Neurol. 2008; 23(9):1028-1035. DOI: 10.1177/0883073808314151 [PubMed: 18287573]

68. Thompson WH, Kalfayan B, Anslow RO. Isolation of California encephalitis group virus from a fatal human illness. Am J Epidemiol. 1965; 81:245-253. [PubMed: 14261030]

69. Rust RS, Thompson WH, Matthews CG, et al. La Crosse and other forms of California encephalitis. J Child Neurol. 1999; 14(1):1-14. DOI: 10.1177/088307389901400101 [PubMed: 10025535]

70. Haddow AD, Bixler D, Odoi A. The spatial epidemiology and clinical features of reported cases of La Crosse virus infection in West Virginia from 2003 to 2007. BMC Infect Dis. 2011; 11:29.doi: 10.1186/1471-2334-11-29 [PubMed: 21269495]

71. McJunkin JE, de los Reyes EC, Irazuzta JE, et al. La Crosse encephalitis in children. N Engl J Med. 2001; 344(11):801-807. DOI: 10.1056/NEJM200103153441103 [PubMed: 11248155]

72. Mayo D, Karabatsos N, Scarano FJ, et al. Jamestown Canyon virus: seroprevalence in Connecticut. Emerg Infect Dis. 2001; 7(5):911-912. [PubMed: 11747714]

73. Centers for Disease Control and Prevention (CDC). Human Jamestown canyon virus infectionMontana, 2009. MMWR Morb Mortal Wkly Rep. 2011; 60(20):652-655. [PubMed: 21617630]

74. McJunkin JE, Nahata MC, De Los Reyes EC, et al. Safety and pharmacokinetics of ribavirin for the treatment of la crosse encephalitis. Pediatr Infect Dis J. 2011; 30(10):860-865. DOI: 10.1097/ INF.0b013e31821c922c [PubMed: 21544005] 


\section{KEY POINTS}

Less than $1 \%$ of West Nile virus-infected individuals develop neuroinvasive disease.

- West Nile virus neuroinvasive disease can manifest as meningitis, encephalitis, acute flaccid paralysis, or a combination of syndromes.

- West Nile virus neuroinvasive disease is more common in individuals older than 60 years of age.

- $\quad$ CSF from patients with West Nile virus neuroinvasive disease may exhibit a neutrophil-predominant pleocytosis.

- West Nile virus encephalitis most commonly causes MRI T2-signal abnormalities in the deep gray nuclei.

- West Nile virus neuroinvasive disease is often diagnosed by measurement of CSF IgM.

- Dengue virus infections are associated with encephalitis and peripheral nerve syndromes.

- $\quad$ Cases of eastern equine encephalitis virus and Venezuelan equine encephalitis virus encephalitis occur during localized epidemic transmission.

- $\quad$ Chikungunya virus is a rapidly emerging virus with rare associations with neurologic disease.

- $\quad$ Chikungunya virus is associated with meningitis and encephalitis during acute infection.

- $\quad$ La Crosse virus causes cases of encephalitis in children.

- $\quad$ Mortality following infection from the California encephalitis group of viruses is low, and outcomes are typically favorable. 


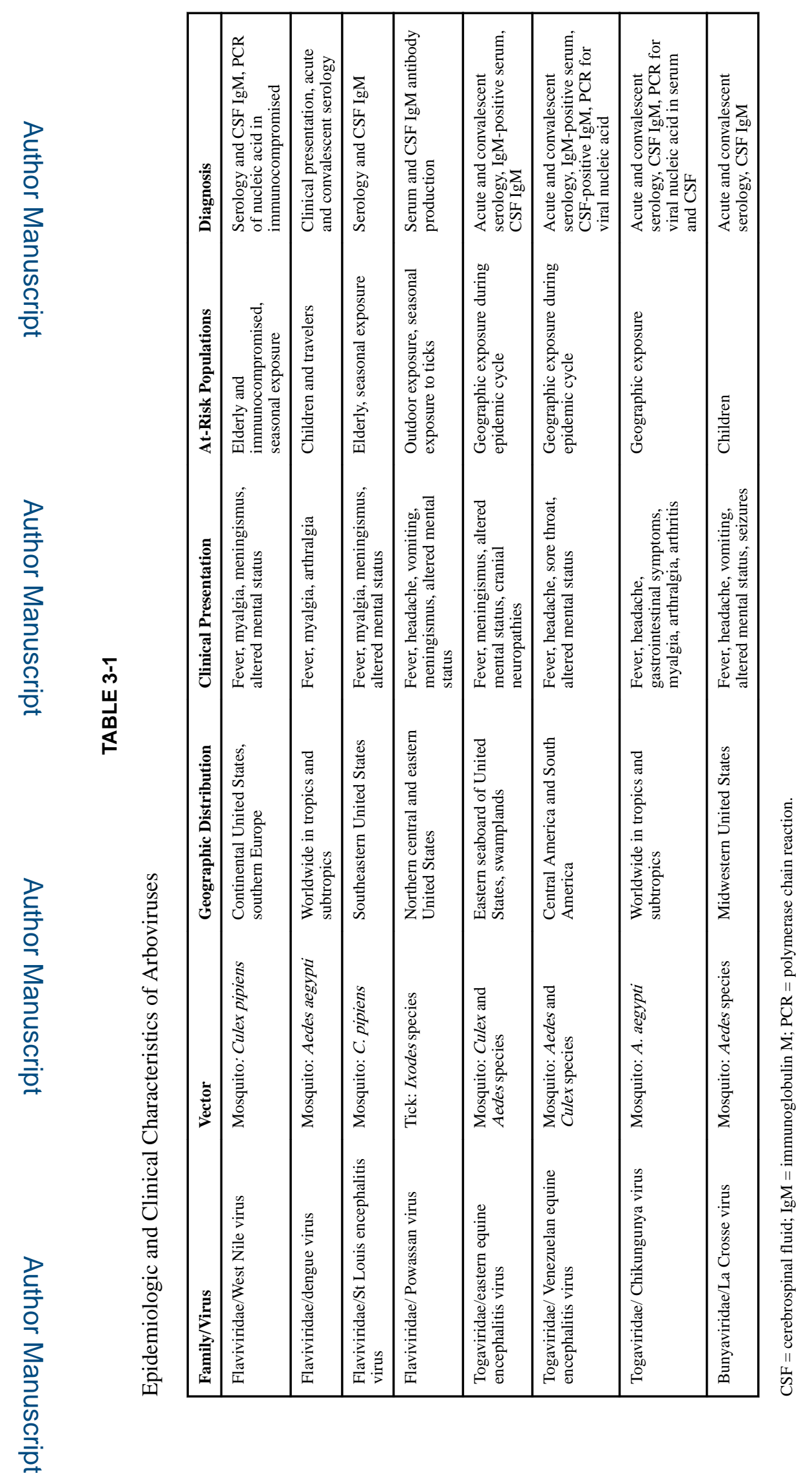

Continuum (Minneap Minn). Author manuscript; available in PMC 2016 December 01. 